논문 및 방사선치료 현황을 통해 본 한국 20 년의 간담도계 암 방사선치료

장원일 ${ }^{*} \cdot$ 서영석 ${ }^{*} \cdot$ 김미숙 $\cdot$ 김희진 ${ }^{2}$

한국원자력의학원 원자력병원 ${ }^{1}$ 방사선종양학과, ${ }^{2}$ 방사선의학정책개발센터

\title{
Academic Trend and Clinical Status of Radiotherapy for Hepatobiliary Cancer Over the Past 20 Years in Korea
}

\author{
Won Il Jang ${ }^{1 *}$, Young-Seok Seo ${ }^{1 *}$, Mi-Sook Kim¹, Heejin Kim² \\ 'Departments of Radiation Oncology and ²Radiation Medicine Policy Development Center, Korea Cancer Center Hospital, Korea Institute \\ of Radiological \& Medical Sciences, Seoul, Korea
}

Received Jul. 28, 2015

Revised Aug. 18, 2015

Accepted Aug. 21, 2015
Background/Aims: To analyze the future trends through the status of radiotherapy in the hepatobiliary cancer in Korea and related articles published in the world.

Methods: Science citation index (SCI) and science citation index expanded (SCIE) articles, published in the 20 years from 1995 until 2014, were searched that contain the keywords related hepatobiliary cancer and radiotherapy using the Scopus. The incidence of hepatobiliary cancer was analyzed using annual reports from the Korea Central Cancer Registry. The status of radiotherapy was analyzed using data obtained form the Korean Society for Radiation Oncology and the National Health Insurance Service.

Results: Total 2,302 papers related radiotherapy for hepatobiliary cancer were searched in the world. By 2014, the cumulative number of papers published by domestic authors was a total 221 pieces. In 1999, total 16,305 hepatobiliary cancer patients were developed, of which 729 patients have been treated with radiotherapy. In 2013, it was expected that total 22,482 hepatobiliary cancer patients would be developed, of which 3,075 patients have been treated with radiotherapy.

Conclusions: Over the past 20 years, South Korea has made clinically and academically remarkable advances in the area of radiotherapy for hepatobiliary cancer. The researchers will continue to announce the results such as an objective status data and published papers in the future. (J Liver Cancer 2015;15:100-105)

Keywords: Liver neoplasms; Radiotherapy; Journal article

\section{Corresponding author: Mi-Sook Kim}

Department of Radiation Oncology, Korea Cancer Center Hospital, Korea Institute of Radiological \& Medical Sciences, 75 Nowon-ro, Nowon-gu, Seoul 01812, Korea

Tel. +82-2-970-1264, Fax. +82-2-970-2412

E-mail; mskim@kirams.re.kr

"Won-II Jang and Young-Seok Seo were co-first authors who equally contributed to this work.

\section{서 론}

간담도계 암은 치사율이 높은 암종 중 하나로 간세포암 종, 담낭암, 간내담관암, 간외담관암 등으로 구분할 수 있 다. ${ }^{1}$ 국내의 경우 2012 년에 간세포암종 진단을 받은 환자는 16,254 명이고 담낭 및 담도암 진단을 받은 환자는 5,131 명 이며, 같은 해 간세포암종으로 사망한 환자는 11,405 명, 담 낭 및 담도암으로 사망한 환자 수는 3,782 명으로 집계되었 
다. ${ }^{2}$ 과거 간세포암종과 담낭 및 담도암은 정상 간조직의 낮은 한계선량으로 인해 방사선치료를 거의 시행하지 않 았지만, 영상유도방사선치료, 세기변조방사선치료, 정위 적체부방사선치료와 같은 치료기술의 발전으로 고선량의 방사선을 종양표적에만 국한하여 조사할 수 있게 되면서 간담도계 암의 방사선치료 비중이 높아지고 있다. ${ }^{3}$ 그러나 간담도계 암의 방사선치료와 관련된 정확한 현황 및 자료 가 전무하여 국내의 기술수준을 가늠하기 어려우며, 때문 에 연구계획 수립 시 필요한 기초자료도 부족한 상황이다. 본 연구에서는 간담도계 암의 전 세계 논문 실적 및 실제 환 자치료 현황자료를 통해 현재 기술수준의 위치와 앞으로 의 발전방향을 제시하고자 한다.

\section{대상과 방법}

\section{1. 논문분석방법}

논문 검색은 Elsevier.B.V사의 Scopus를 이용하였다. 1995 년부터 2014년까지 발표된 논문들 중 논문 제목, 초록 그리 고 논문 키워드에 간 - 담도계암과 방사선치료와 관련된 단 어가 포함된 논문들을 검색하여 국가별 현황과 연도별 논 문 편수를 분석하였다. 논문 검색에 사용된 단어들은 표 1 에 나열하였으며, 논문 검색 시 해당 단어들을 조합한 검색

Table 1. Keywords list of article search

\begin{tabular}{ll}
\hline Cancer keywords & \multicolumn{1}{c}{ Technique keywords } \\
\hline Hepatocellular carcinoma & Radiation therapy \\
Hepatocellular cancer & Radiation treatment \\
Cholangiocarcinoma & Radiotherapy \\
Gallbladder cancer & Stereotactic radiation therapy \\
& Stereotactic radiation treatment \\
& Stereotactic radiotherapy \\
& Stereotactic body radiation therapy \\
& Stereotactic body radiation treatment \\
& Stereotactic body radiotherapy \\
& Stereotactic ablative radiation therapy \\
& Stereotactic ablative radiation treatment \\
& Stereotactic ablative radiotherapy \\
& Stereotactic ablative body radiation \\
& therapy \\
& Stereotactic ablative body radiation \\
& treatment \\
& Stereotactic ablative body radiotherapy \\
& Stereotactic radiosurgery \\
& Stereotactic radiation surgery \\
\hline
\end{tabular}

식을 이용하였다. 검색 시 발생한 중복자료들은 모두 제외 하였다. 국가별 현황은 책임저자가 소속된 기관의 국적을 기준으로 하였으며, 이때 책임저자 정보가 없는 경우는 제 외하였다.

\section{2. 암 환자 현황분석 방법}

간담도계 암 환자 현황은 국가 암 정보센터에서 발표한 1999년부터 2012년까지의 통계자료와 2013년도 암 환자 예측치를 이용하였다. ${ }^{4}$ 방사선치료 환자의 경우 1999년부 터 2006년까지는 대한방사선종양학회에서 발표한 논문 통 계자료를 활용하였고, ${ }^{5-8}$ 2009년과 2013년은 건강보험심사 평가원이 보유하고 있는 건강보험청구자료를 이용해 분석 하였다. 자료 신청 기준은 2009년과 2013년에 진료를 받은 환자들 중에서 상병코드가 악성신생물이고 방사선치료와 관련된 행위코드를 가진 사람들을 조건으로 하였다. 청구 자료 산출 조건은 표 2 와 같다. 건강보험청구자료는 건강보 험심사평가원에서 제공하는 서버에 접속해 통계프로그램 인 SAS (SAS Inc., Cary, NC, USA)를 이용하여 암 환자의 방 사선치료 현황을 상병별로 분석하였다. 이 중 간 - 담도계 암 환자의 방사선치료 현황은 전체 자료 중 상병코드가 $\mathrm{C} 22$ 부 터 C24인 결과를 추출하였다.

\section{결 과}

\section{1. 국내외 방사선치료 논문 발표 현황}

1995년부터 2014년 사이에 간담도계 암에 대한 방사선치 료 관련 논문을 Scopus를 이용하여 검색한 결과 총 2,302편 의 논문이 검색되었다. 1995 년도 총 31편으로 시작하여 꾸 준히 증가추세를 보이며, 2014년도에는 총 289편의 논문이

Table 2. General characteristics of malignant neoplasms in radiation therapy

\begin{tabular}{ll}
\hline List & \multicolumn{1}{c}{ Criterion } \\
\hline Treatment period & 2009.1.1-2009.12.31, 2013.1.1-2013.12.31 \\
Type of healthcare facilities & Tertiary, Secondary \\
Type of insurance & Health insurance, Medical aid \\
Hospital region & Nation \\
Sex & Male, Female \\
Age & All ages \\
\hline
\end{tabular}


발표되었다. 국내 간담도계 암의 외부방사선조사치료 분 야 논문은 1999년에 처음으로 1편의 논문이 발표되었으며, 2014년도에는 총 47편의 논문이 발표되었다. 2014년까지 국내저자의 누적 논문 발표는 총 221 편으로 전 세계적으로 간담도계 방사선치료 논문 수의 $10 \%$ 에 해당된다(Fig. 1).

국내 간담도계 암에 대한 정위적체부방사선치료에 대한 논문은 2006년 처음으로 1편의 논문이 발표되었으며, 해마 다 빠른 증가추세를 보였다. 2014년도까지 총 26편의 정위 적체부방사선치료 관련 논문이 발표되었는데, 이는 국내 간담도계 방사선치료관련 누적 논문 수의 $12 \%$ 에 해당된다

(Fig. 2).

주요 국가 현황을 보면, 1995년부터 2014년 사이에 발표 된 총 2,302 편의 논문 중 상위 10 개국의 논문이 1,943 편으로 전체 논문의 약 $84 \%$ 를 차지하고 있다. 20 년간의 전체 누적 논문 수를 보면 미국이 총 508 편으로 1 위이고, 그 뒤를 일 본, 중국 등이 잇고 있다. 한국의 경우 2014년까지 총 221편
을 발표해 4위를 기록하였다(Fig. 3A). 하지만 최근 2013년 과 2014년에는 미국에 이어 두 번째로 많은 논문을 발표하 고 있다(Fig. $3 \mathrm{~B}$ ).

\section{2. 국내 방사선치료 현황}

국내 간담도계암 환자는 꾸준히 증가하고 있다. 암 발생 률 통계가 집계되기 시작한 1999년에는 16,305명의 환자가 발생하였고, 2013년도에는 22,482명이 될 것으로 전망하고 있다(Fig. 4).

간담도계암 환자의 방사선치료 현황은 1999 년에는 729 명의 환자가 방사선치료를 받아 전체 간담도계암 환자의 약 $4 \%$ 가량이 방사선치료를 받은 것으로 나타났다. 하지만 2006년을 기점으로 방사선치료를 받은 간담도계암 환자 수가 급격하게 늘어나면서, 2013년에는 3,075명의 환자가 방사선치료를 받아 전체 환자의 약 $14 \%$ 가 방사선치료를

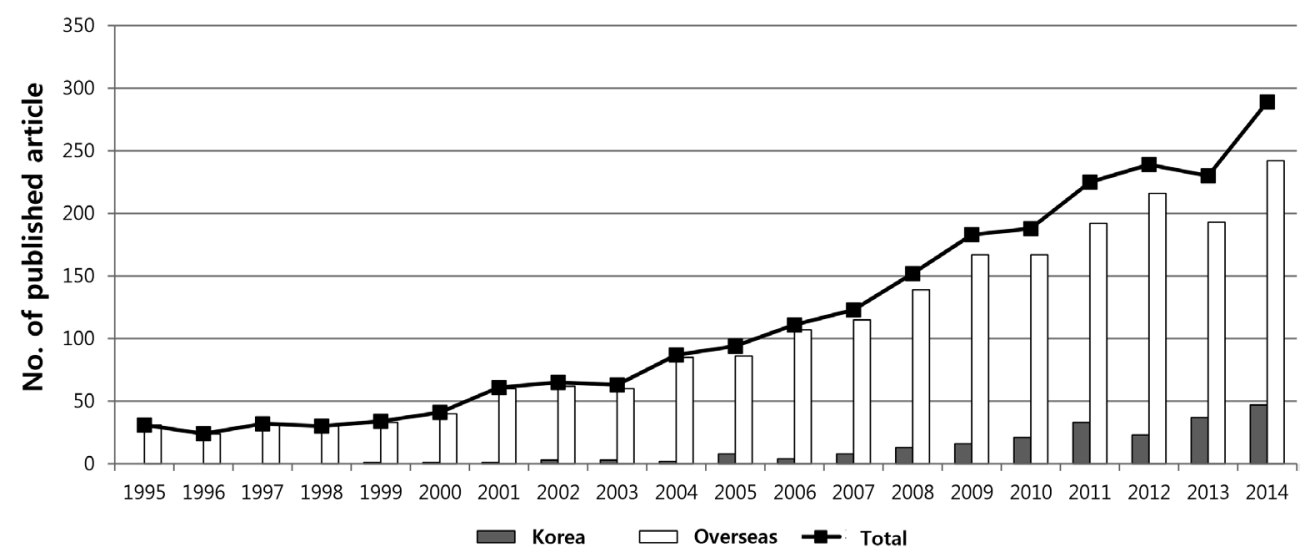

Figure 1. Number of publication articles the year from 1995 to 2014.

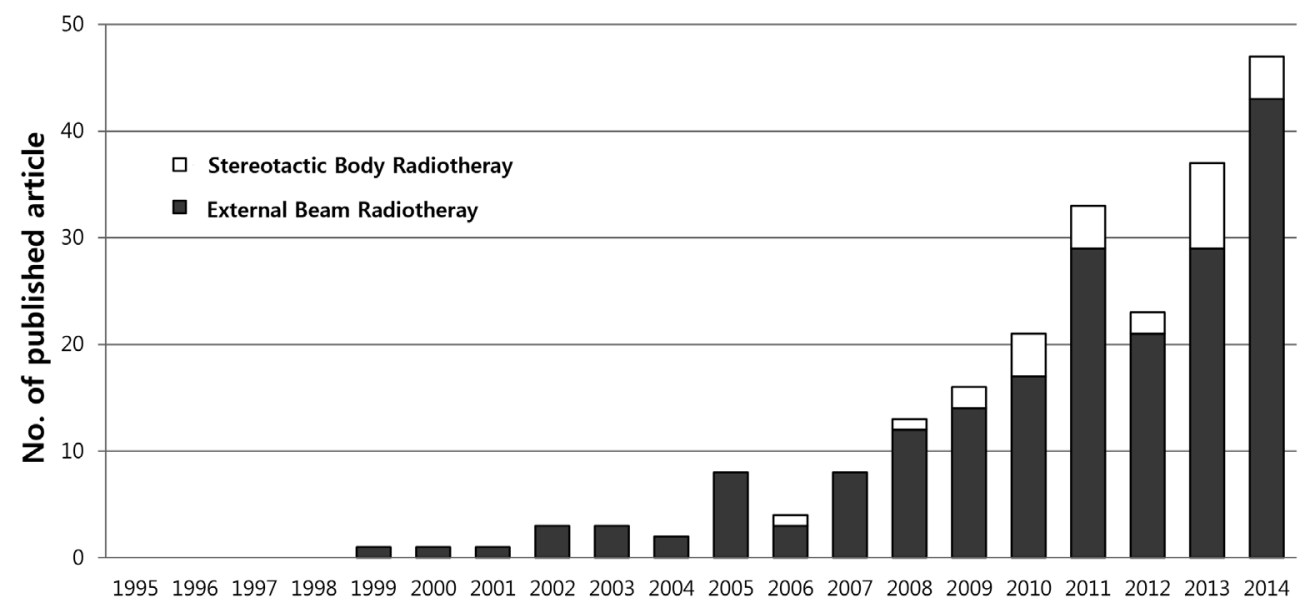

Figure 2. Number and proportion of the articles by radiation therapy techniques. 


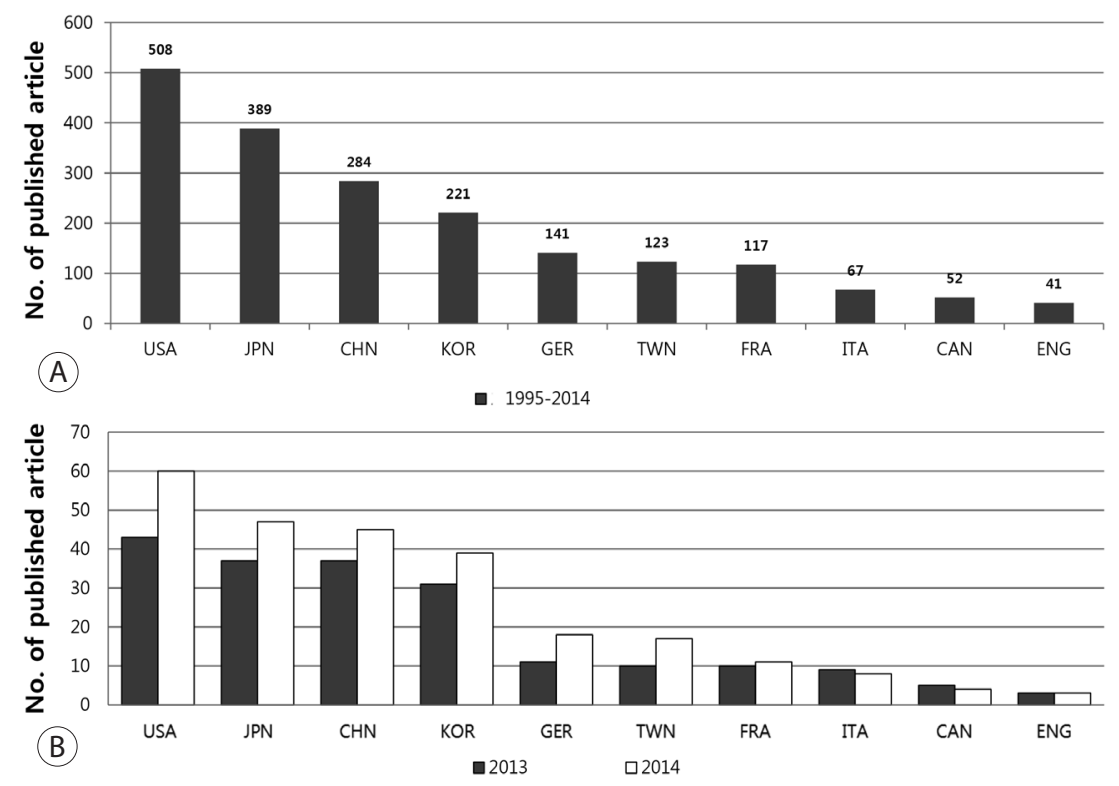

Figure 3. Top 10 countries which ranked in the number of published articles from 1995 to 2014 (A), from 2013 to 2014 (B).

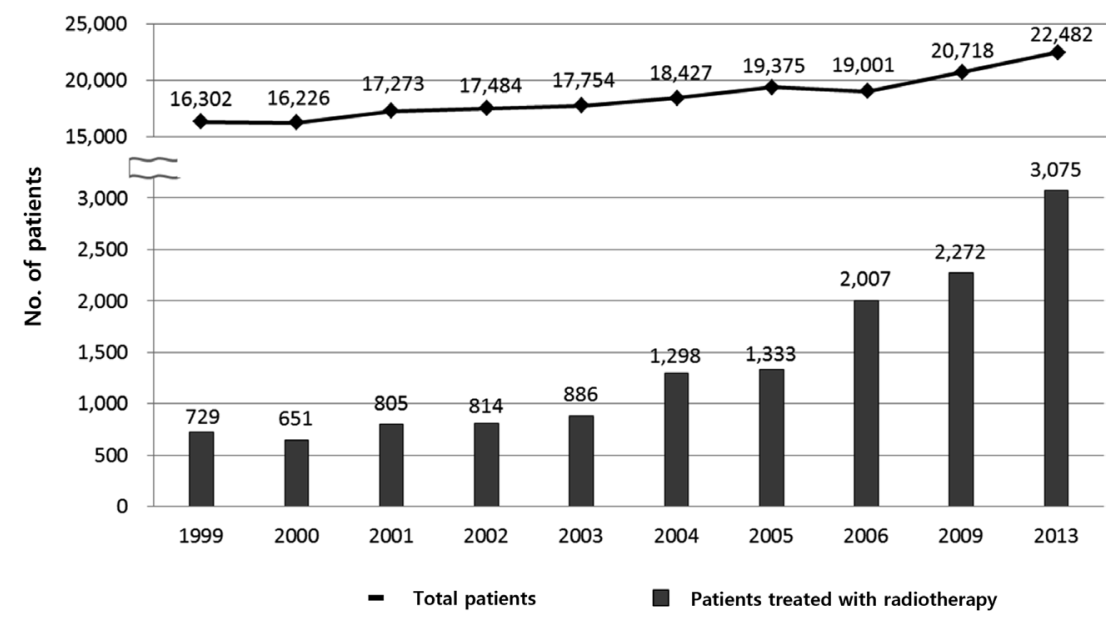

Figure 4. Status of the radiation therapy in hepatobilliary cancer patients.

받았을 것으로 보인다(Fig. 4).

\section{고 찰}

원발성 간담도암의 주된 근치적 치료는 수술이다. 하지 만 종양의 크기 및 위치, 간기능, 동반질환 등을 고려할 때 수술이 불가능한 경우가 대부분이다. ${ }^{9}$ 간종양의 경우 비교 적 방사선에 민감한 종양으로 알려져 있으나 방사선치료 가 간종양 치료에 있어 주된 역할을 하지 못해 왔었다. 이는 정상 간조직 역시 방사선에 민감하여 간종양의 국소조절 을 이룰 만큼의 충분한 방사선량을 전달할 수 없었기 때문
이었다. 그러나 지난 20 여 년간 방사선치료 기술의 눈부신 발달은 간 부위로 충분한 방사선 선량을 안전하게 전달할 수 있게 하였고, 간담도암에서의 방사선치료의 역할을 넓 혀왔다. ${ }^{10,11}$

1990년 Lawrence 등 ${ }^{12}$ 이 간내 종양의 방사선치료 시 종양 에 전달할 선량을 결정하기 위한 정상간조직의 선량체적 히스토그람(dose volume histogram)을 적용한 임상프로토 콜을 발표한 이후, 간내 종양에 대한 3 차원 입체조형 방사 선치료(3-dimetional conformal radiotherapy, 3D-CRT)가 안전하게 수행 가능해짐에 따라 간담도계 암에서 근치적 목적의 방사선치료가 늘어나게 되었다. 그리고 2000년대 
들어서며 4차원 전산화단층촬영(4-dimensional computed tomography) 기술 및 정위적체부방사선치료 기계의 발달 로 간담도암의 방사선치료는 또 한 번의 도약을 이루어냈 으며, 최근 양성자치료 및 중립자치료가 간담도계 암으로 의 적응증을 넓혀가고 있다. ${ }^{13}$ 이러한 간담도계 암 방사선 치료 기술 발달의 역사가 본 연구의 국내외 방사선치료 논 문 현황에서도 그대로 반영되어 나타난 것으로 보인다(Fig. 1). 2000 년까지 완만한 증가세를 보이던 간담도계 암에 대 한 방사선치료 논문 발표 수가 2000년 들어서며 급속히 증 가하기 시작하였다. 이는 1990 년대 3D-CRT가 간담도계 암 에 적용되기 시작한 후 전 세계적으로 선형가속기의 보급 이 일반화되면서 간내 방사선치료가 늘어나고, 그 결과로 발표된 논문 수도 늘어난 것으로 분석된다.

국내의 간담도계 암 방사선치료 관련 논문 발표는 2005 년을 기점으로 가파르게 상승하기 시작하였다(Fig. 2). 지 난 20 여년간 간담도계암의 방사선치료 관련 논문 건수에 서 전 세계 주요 국가 중 한국이 4 위를 차지하였으나, 최근 2013년, 2014년도에 발표된 논문 건수를 보면 미국에 이어 2 위를 차지하는 고무적인 결과를 보였다(Fig. 3). 이러한 상 승세는 간담도계 암의 발생률이 한국에서 증가했다기 보 다 국내에서 $3 \mathrm{D}-\mathrm{CRT}$ 의 간내 종양 치료의 일반화 및 정위 적체부방사선치료의 보급으로 간담도암에 대한 방사선치 료 건수의 증가에서 기인한 것으로 분석된다. 2012년 국가 암등록통계자료에 따르면 1999년부터 2012년 사이에 간담 도계암의 발생빈도는 오히려 감소하는 양상을 보이고 있 다. ${ }^{2}$ 반면, 대한 방사선종양학회 전국 통계 자료에 따르면 1999년 729건으로 전체 간담도계암 환자 발생 대비 약 $4 \%$ 에 불과하던 방사선치료 건수 ${ }^{8}$ 가 국내에서는 2002년 원자 력병원에서 사이버나이프를 국내 최초로 도입하면서 간담 도계암의 정위적체부방사선치료 건수가 늘어나기 시작하 였다. 이러한 정위적체부방사선치료를 시행한 환자가 수 년간 누적되고, 생존분석이 시작되면서 2006년 이후 정위 적체부방사선치료 관련 논문 발표도 늘어난 것으로 판단 된다.

그동안 특정암에 대한 특정 치료에 대한 건수를 조사하 기 위해서는 관련 학회 혹은 몇몇 대형병원을 중심으로 설 문지 조사와 같은 방법으로 연구를 진행해 왔었다. 하지만 설문지 조사 방법은 응답률이 저조하며, 특히 응답자의 응 답내용이 기억이나 혹은 객관적이지 못한 기록에 의존할 수 있으므로 바이어스(bias)가 발생할 위험이 크다. 이러한 단점을 보완하기 위해 본 연구에서는 건강보험 심사평가
원의 청구자료를 이용하여 국내 간담도계암 환자에서의 방사선치료 건수를 조사하였다. 우리나라는 전 국민 건강 보험 시행으로 인하여 전체 국민의 $98 \%$ 가 건강보험이 적 용되며, 급여항목에 대한 보험 청구건은 건강보험 심사평 가원의 청구자료에 전수 저장된다. 따라서 청구자료를 활 용한 분석 방법은 전 국민을 대상 범위로 확대할 수 있고, 객관적인 자료를 수집할 수 있는 장점이 있다. 하지만 비급 여항목에 대한 청구는 이루어지지 않으므로 이에 대한 연 구를 진행할 수 없는 것은 단점이다. 예를 들어 간담도계암 에서 사이버나이프를 이용한 정위적체부방사선치료의 경 우 최근 들어 급여항목으로 지정되었으므로, 본 연구의 결 과 중 2009년, 2013년 방사선치료 건수에서는 사이버나이 프를 이용한 정위적체부방사선치료 건수는 누락되어 있다 (Fig. 4). 따라서 실제 방사선치료 건수는 본 연구의 결과보 다 더 많을 것으로 예상된다.

지난 20여년간 한국은 간담도계암 방사선치료 영역에서 임상적 및 학술적으로 눈부신 발전을 이루어냈다. 아직은 방사선치료가 간내 종양을 치료하기 위한 각종 가이드라 인에서 표준치료로 인정받기에는 근거가 부족한 상황이지 만, 현재와 같이 국내외 연구성과가 급증하는 상황이라면 가까운 미래에 가이드라인의 변화가 있을 수 있을 것으로 기대된다. 본 연구진은 향후에도 청구자료를 활용한 객관 적인 현황자료 및 논문 발표 실적 등을 지속적으로 발표할 예정이다.

\section{ACKNOWLEDGMENT}

This study was supported by the scientific research fund of 'The Korean Liver Cancer Study'.

\section{요 약}

목적: 전 세계에 발표된 간담도계 암의 방사선치료와 관 련된 논문 현황과 우리나라의 간담도계 암 환자의 방사선 치료 현황을 조사하여 미래 트랜드를 분석하고자 하였다.

대상과 방법: 논문 현황은 1995년부터 2014년까지 20년 간 전 세계에서 발표된 science citation index (SCI) 및 science citation index expanded (SCIE) 논문 중 간담도계 암과 방사선치료 관련 키워드가 포함된 논문들을 검색하여 전 체 현황, 국내 현황 그리고 주요국가별 논문발표 현황을 조 사하였다. 전체 간 - 담도계암 발생률과 국립암센터의 암종 
별 발생현황 자료와 예측자료를 이용하였다. 방사선치료 현황은 1999년부터 2006년까지는 대한방사선종양학회 발 표자료를 인용하였고, 2009년과 2013년은 건강보험심사평 가원의 청구데이터 분석을 통해 도출하였다.

결과: 이 기간 동안 전 세계에서 2,302편의 간담도계암 에서 방사선치료 관련 논문이 발표되었다. 2014년까지 국 내저자의 누적 논문발표건수는 221편이었다. 1999년 국내 간담도계 암 환자 발생건수는 16,305 명이었으며, 이 중 방 사선치료를 시행한 환자는 729명이었다. 그러나 2013년도 에는 총 22,482 명의 간담도계암 환자가 발생하였고, 이중 3,075 명의 환자가 방사선치료를 받았다.

결론: 과거에는 간담도계암 치료 시 외과적 절제가 우선 적으로 시행되었지만, 방사선치료기법의 발달로 점차 방 사선치료 사례가 늘어나는 추세이다. 이에 따라 간담도계 암의 방사선치료와 관련된 논문들도 빠른 속도로 증가하 고 있다.

중심 단어: 간종양; 방사선치료; 저널 논문

\section{Conflicts of Interest}

The authors have no conflicts to disclose.

\section{REFERENCES}

1. Benson $A B$ 3rd, Abrams TA, Ben-Josef E, Bloomston PM, Botha $J F$, Clary BM, et al. NCCN clinical practice guidelines in oncology: hepatobiliary cancers. J Natl Compr Canc Netw 2009;7:350-391.

2. Jung KW, Won YJ, Kong HJ, Oh CM, Cho H, Lee DH, et al. Cancer statistics in Korea: incidence, mortality, survival, and prevalence in 2012. Cancer Res Treat 2015;47:127-141.

3. Feng M, Ben-Josef E. Radiation therapy for hepatocellular carcinoma. Semin Radiat Oncol 2011;21:271-277.

4. Jung KW, Won YJ, Kong HJ, Oh CM, Seo HG, Lee JS. Prediction of cancer incidence and mortality in Korea, 2013. Cancer Res Treat 2013:45:15-21.

5. Yoo SY, Kim MS, Ji YH, Yang KM, Yoo HJ. Nationwide statistics of the Korean Society for Radiation Oncology (1999 2001). J Korean Soc Ther Radiol Oncol 2004;22:234-236.

6. Kim MS, Ji YH, Cho CK, Yang KM, Yoo HJ, Song YS. Nationwide statistics of the Korean Society for Radiation Oncology (2002 2004). J Korean Soc Ther Radiol Oncol 2006;24:77-80.

7. Kim MS, Ji YH, Yoo SY, Cho CK, Yang KM, HYoo HJ. Nationwide statistics of the Korean Society for Radiation Oncology (2005). J Korean Soc Ther Radiol Oncol 2006;24:207-209.

8. Ji YH, Kim MS, Yoo SY, Choi MS, Yoo DH, Jung HJ. Nationwide statistics of the Korean Society for Radiation Oncology (2006). J Korean Soc Ther Radiol Oncol 2008;26:131-133.

9. Forner A, Llovet JM, Bruix J. Hepatocellular carcinoma. Lancet 2012;379:1245-1255.

10. Klein J, Dawson LA. Hepatocellular carcinoma radiation therapy: review of evidence and future opportunities. Int J Radiat Oncol Biol Phys 2013:87:22-32.

11. Aitken $\mathrm{KL}$, Hawkins MA. The role of radiotherapy and chemoradiation in the management of primary liver tumours. Clin Oncol $(R$ Coll Radiol) 2014;26:569-580.

12. Lawrence TS, Tesser RJ, ten Haken RK. An application of dose volume histograms to the treatment of intrahepatic malignancies with radiation therapy. Int J Radiat Oncol Biol Phys 1990;19:1041-1047.

13. Tanguturi SK, Wo JY, Zhu AX, Dawson LA, Hong TS. Radiation therapy for liver tumors: ready for inclusion in guidelines? Oncologist 2014;19:868-879. 